\title{
Metal-free synthesis of fully substituted pyridines via ring construction based on the domino reactions of enaminones \\ and aldehydes
}

\author{
Jie-Ping Wan, ${ }^{\mathrm{a}, *}$ Yanfeng Jing, ${ }^{\mathrm{a}}$ Changfeng Hu, ${ }^{\mathrm{b}}$ Shouri Sheng ${ }^{\mathrm{a}, *}$ \\ ${ }^{a}$ College of Chemistry and Chemical Engineering, Jiangxi Normal University, Nanchang 330022, \\ P.R. China. ${ }^{b}$ College of Basic Medical Sciences, Zhejiang Chinese Medical University, Hangzhou, \\ Zhejiang 310053, China. \\ Email: wanjieping@jxnu.edu.cn; shengsr@jxnu.edu.cn
}

\section{Contents}

General information...........................................................

References....................................................................

${ }^{1} \mathrm{H}$ and ${ }^{13} \mathrm{C}$ NMR spectra of all products................................S2-S19

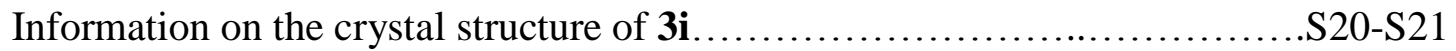

\section{General information}

Enaminones 1 and enaminoesters $\mathbf{4}$ were synthesized following literature process. ${ }^{1-2}$ All other chemicals and solvents used in our experiments were obtained from commercial sources and used directly without further treatment. All reactions were performed at open air atmosphere and monitored with TLC. ${ }^{1} \mathrm{H}$ and ${ }^{13} \mathrm{C}$ NMR were recorded in $400 \mathrm{MHz}$ apparatus using $\mathrm{CDCl}_{3}$ as solvent. The frequency used for ${ }^{1} \mathrm{H}$ and ${ }^{13} \mathrm{C}$ NMR measurement were $400 \mathrm{MHz}$ and $100 \mathrm{MHz}$, respectively. The chemical shifts were recorded in ppm using TMS as internal standard.

\section{References}

1. Zhao, Y.; Zhao, J.; Zhou, Y.; Lei, Z.; Li, L.; Zhang, H. New. J. Chem. 2005, 29, 769-772.

2. Ramtohul, Y. K.; Chartrand, A. Org. Lett. 2007, 9, 1029-1032. 
NMR spectra

${ }^{1} \mathrm{H}$ and ${ }^{13} \mathrm{C}$ NMR spectra of $\mathbf{3 a}$
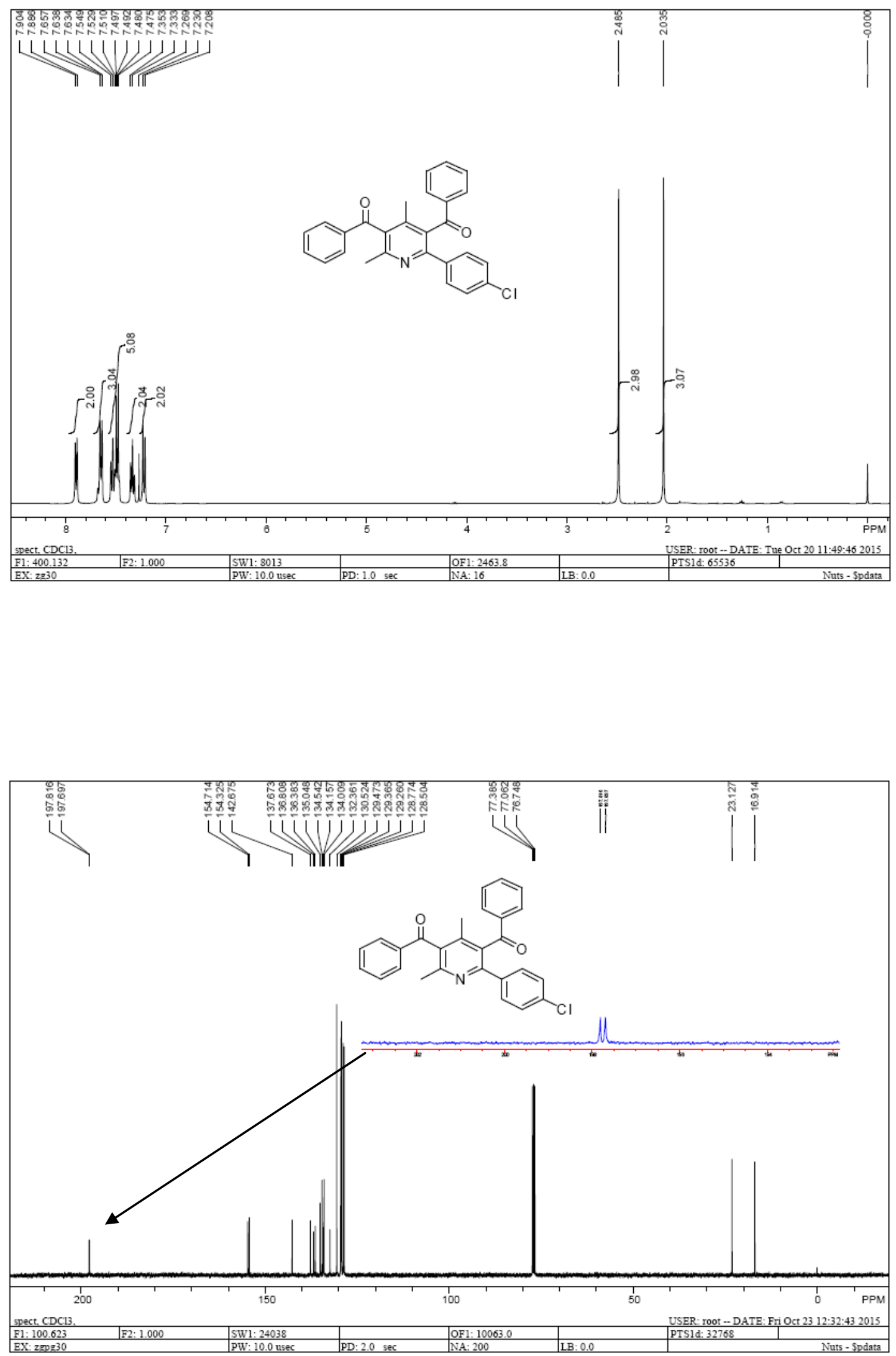
${ }^{1} \mathrm{H}$ and ${ }^{13} \mathrm{C}$ NMR spectra of $\mathbf{3 b}$
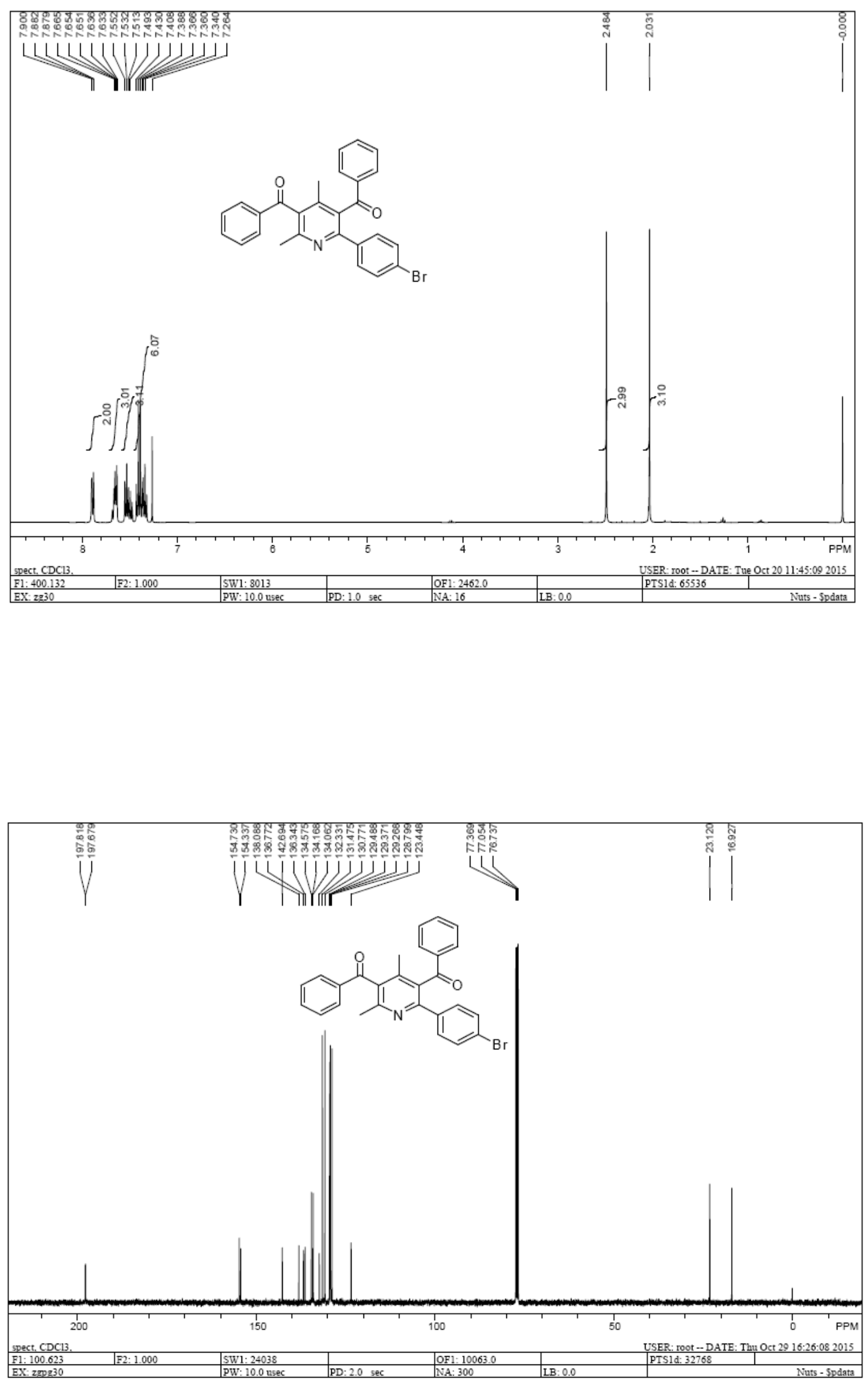
${ }^{1} \mathrm{H}$ and ${ }^{13} \mathrm{C}$ NMR spectra of $\mathbf{3 c}$
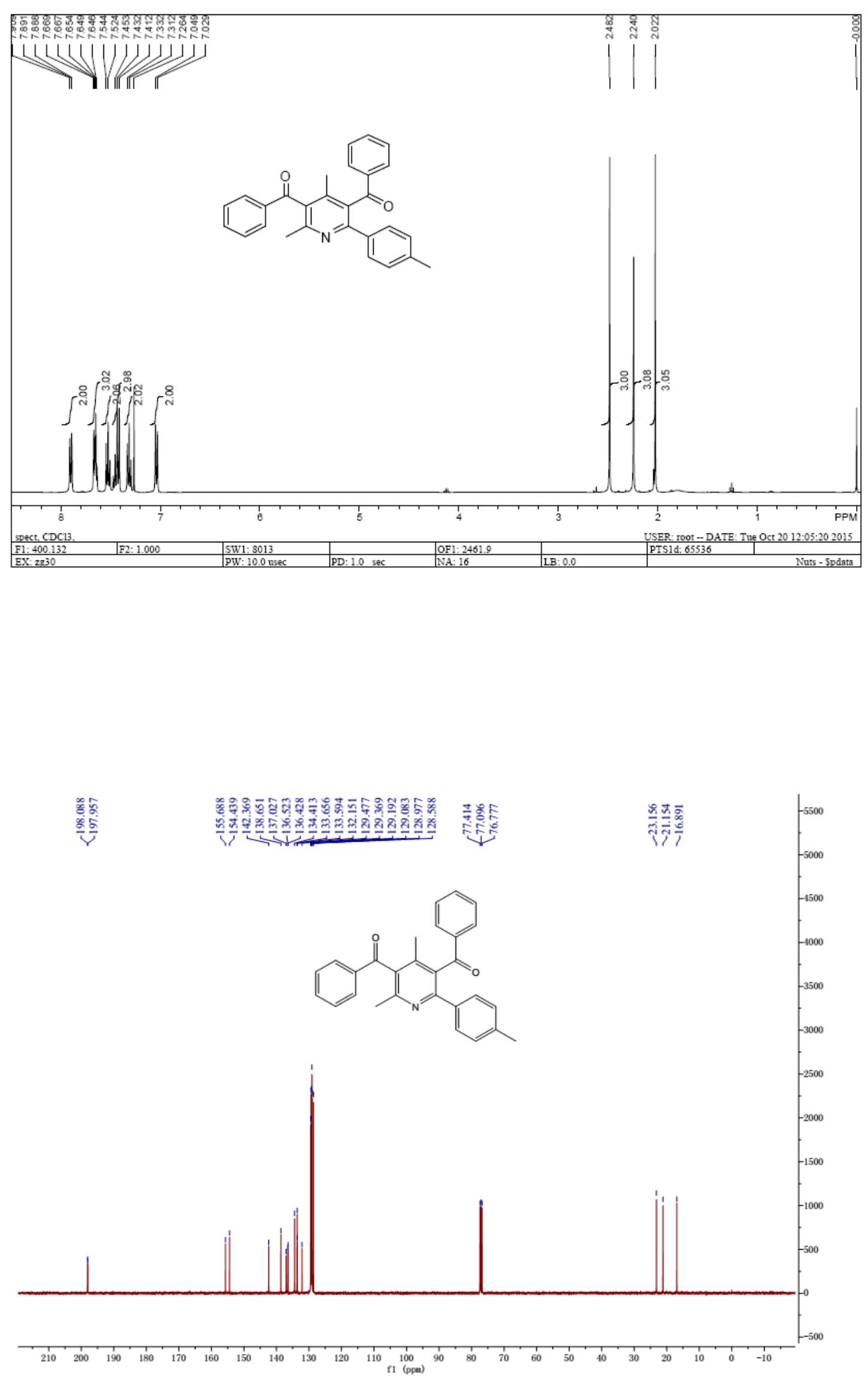
${ }^{1} \mathrm{H}$ and ${ }^{13} \mathrm{C}$ NMR spectra of $\mathbf{3 d}$
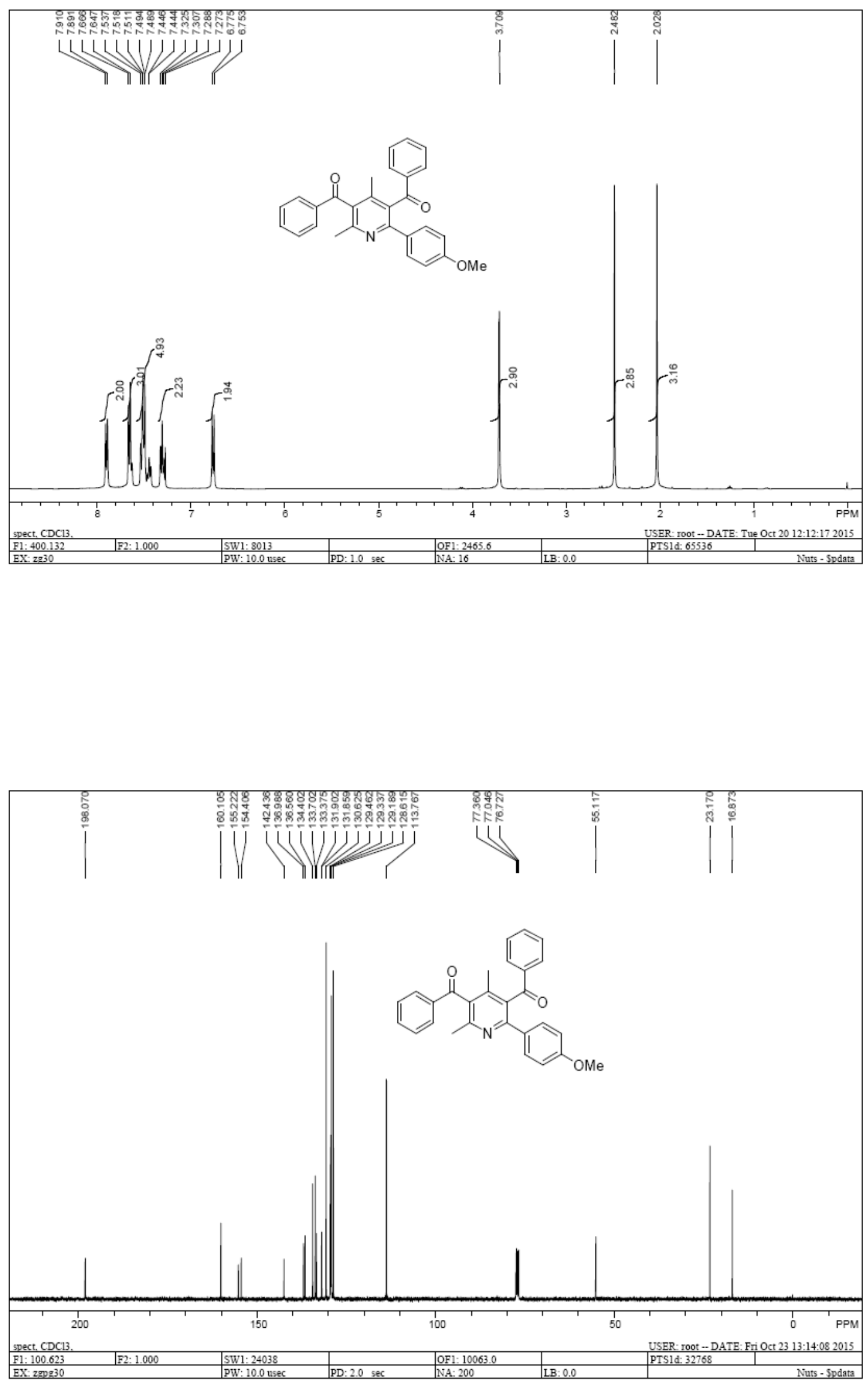
${ }^{1} \mathrm{H}$ and ${ }^{13} \mathrm{C}$ NMR spectra of $\mathbf{3 e}$
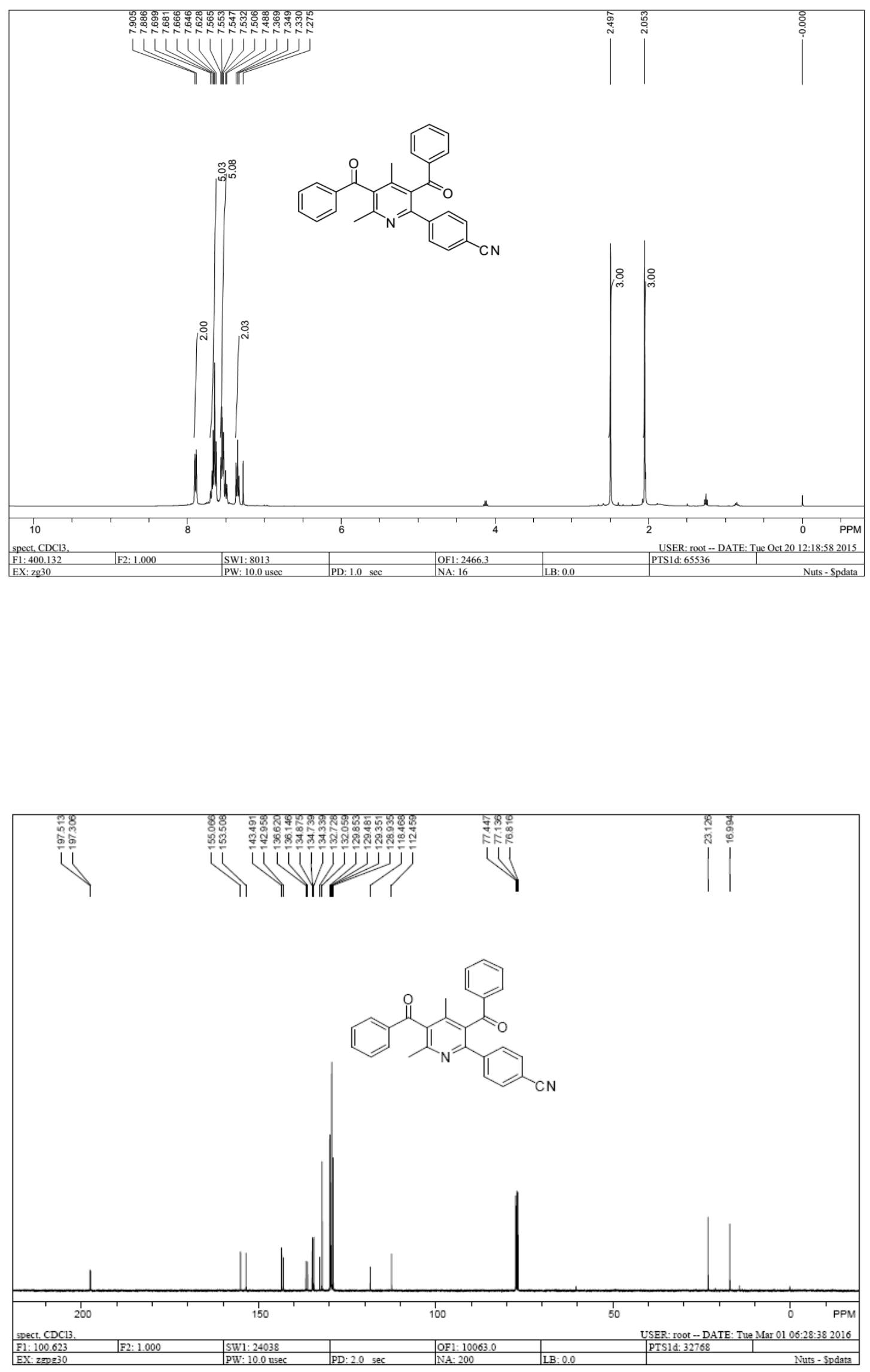
${ }^{1} \mathrm{H}$ and ${ }^{13} \mathrm{C}$ NMR spectra of $\mathbf{3 f}$
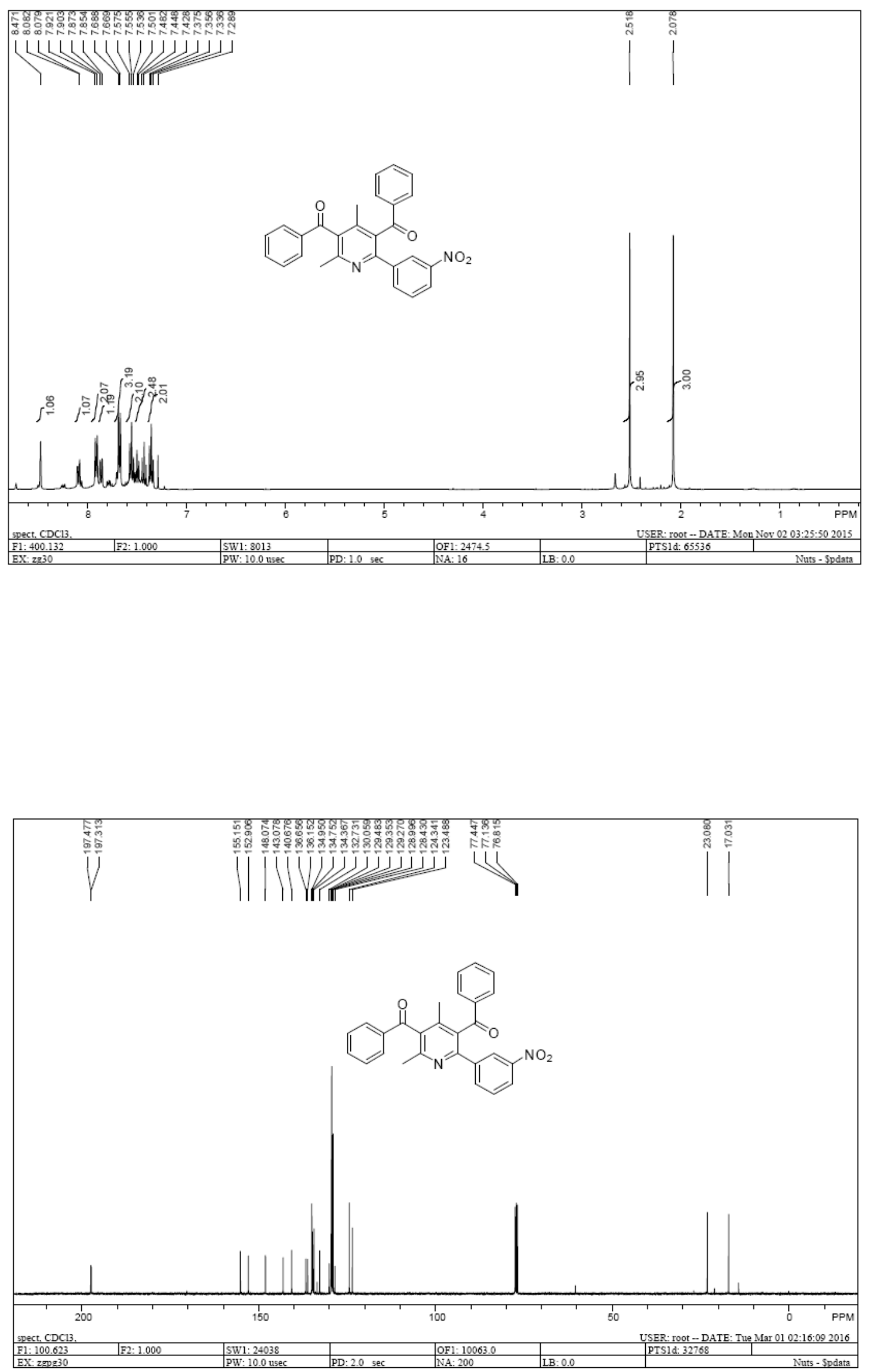
${ }^{1} \mathrm{H}$ and ${ }^{13} \mathrm{C}$ NMR spectra of $\mathbf{3 g}$
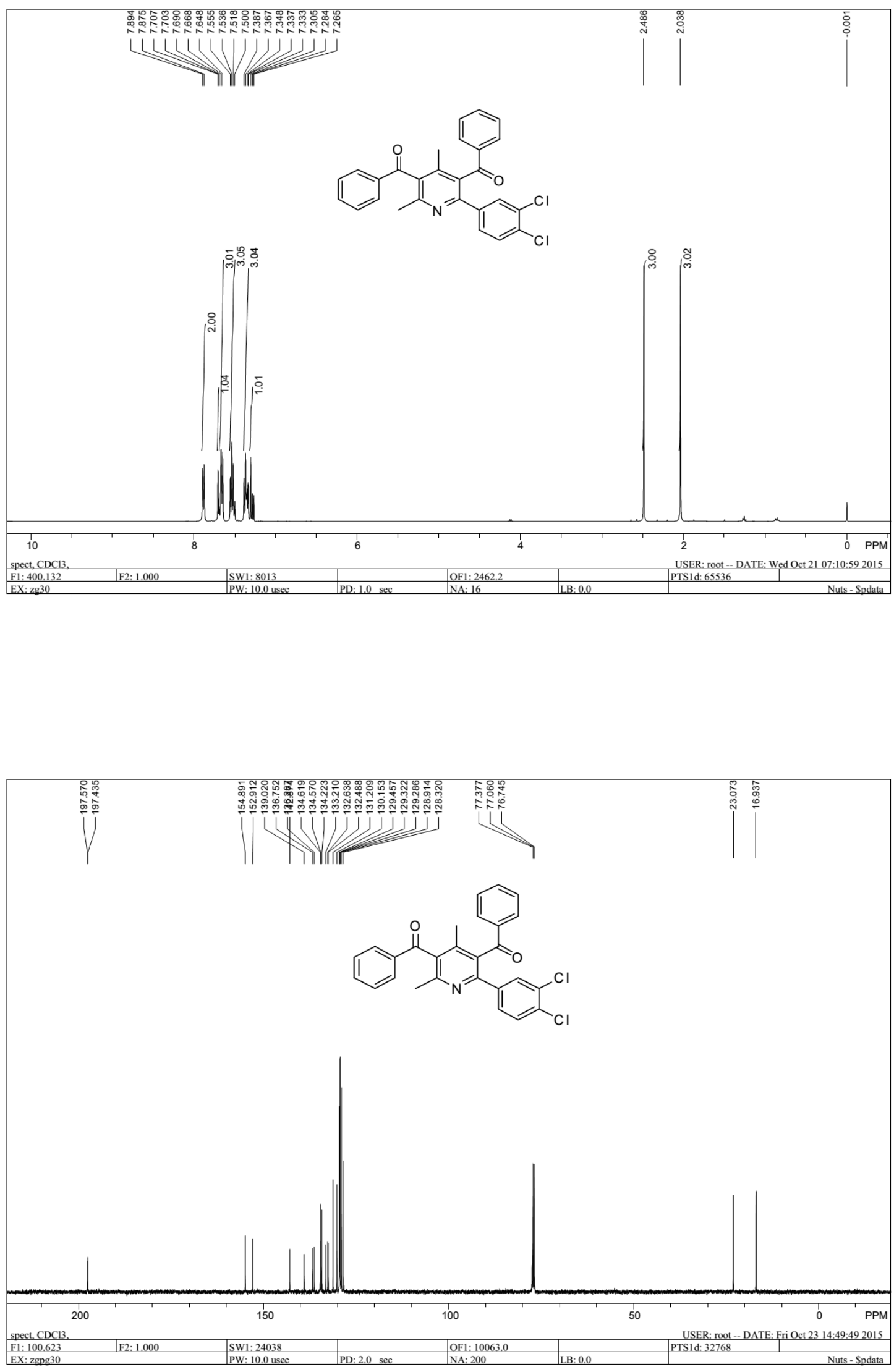
${ }^{1} \mathrm{H}$ and ${ }^{13} \mathrm{C}$ NMR spectra of $\mathbf{3 h}$
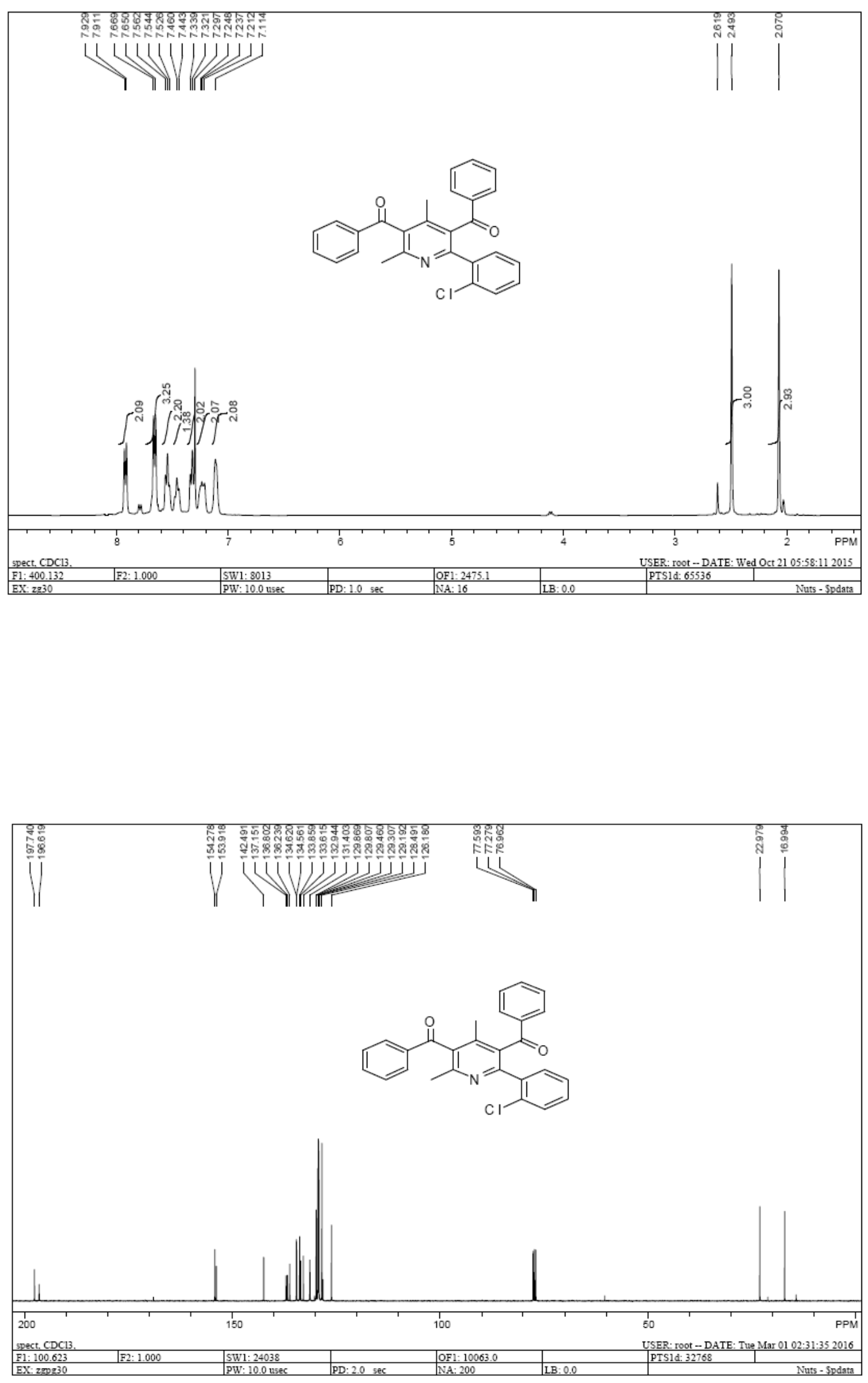
${ }^{1} \mathrm{H}$ and ${ }^{13} \mathrm{C}$ NMR spectra of $\mathbf{3 i}$
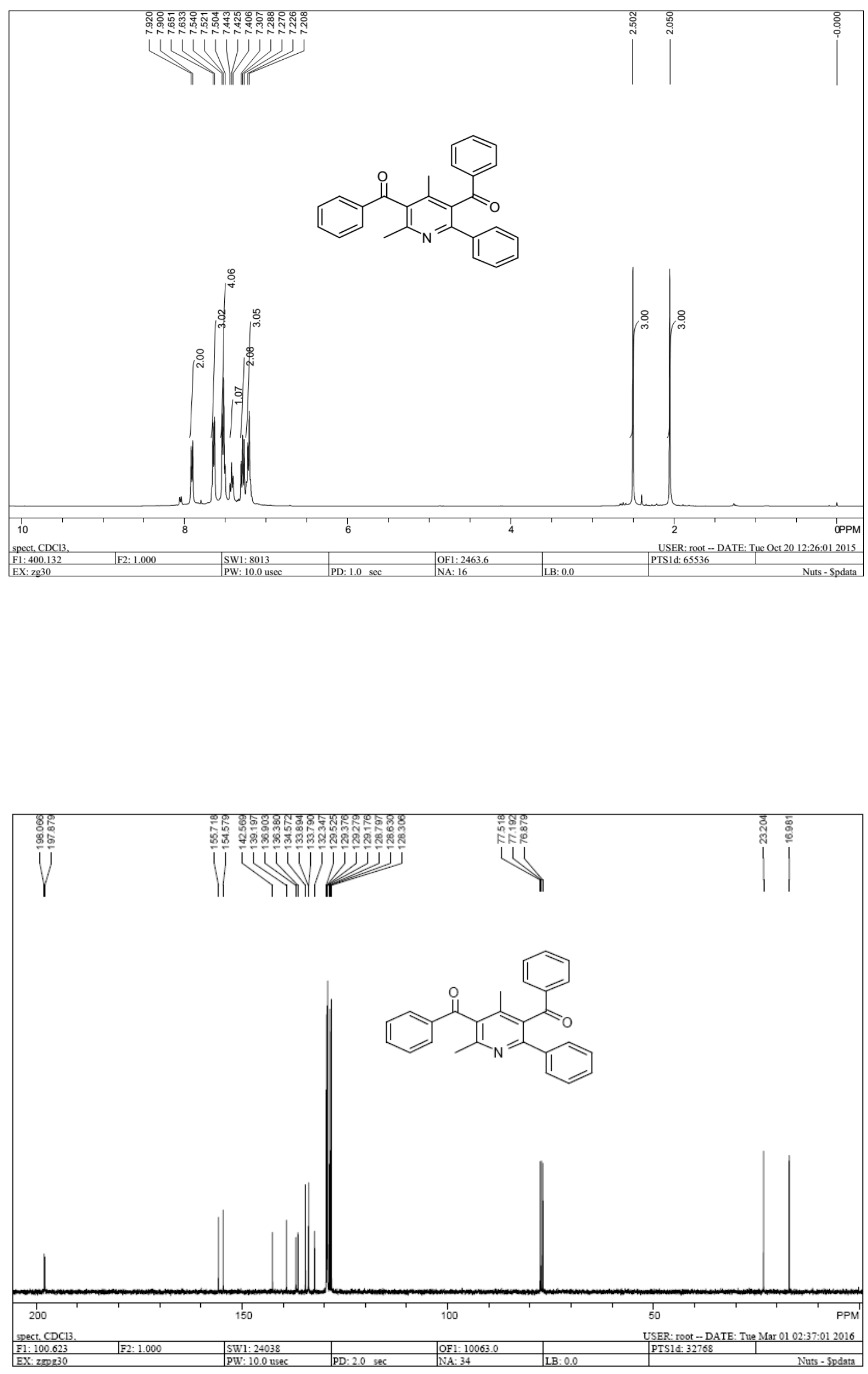

S10 

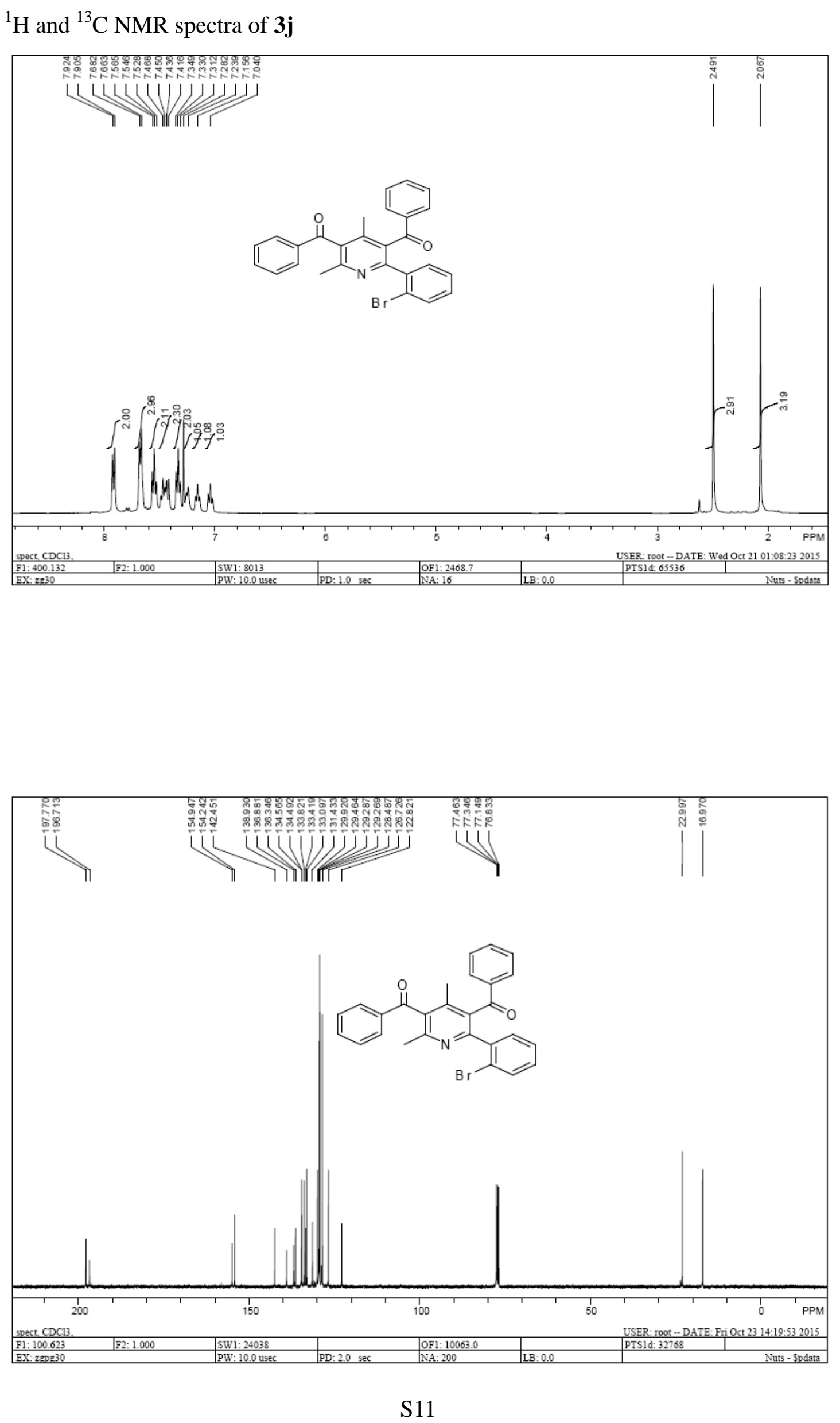


\section{${ }^{1} \mathrm{H}$ and ${ }^{13} \mathrm{C}$ NMR spectra of $\mathbf{3 k}$}
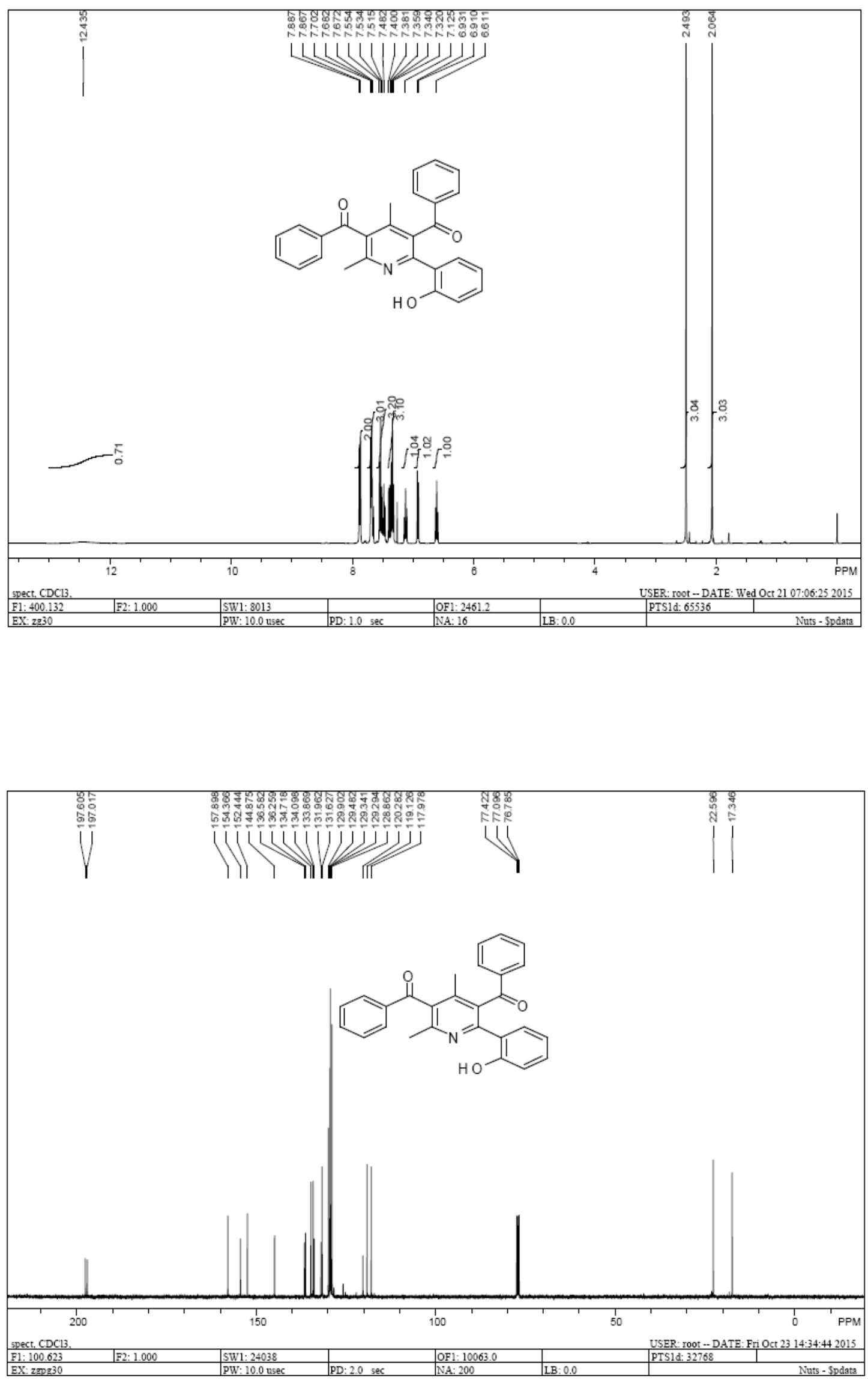
${ }^{1} \mathrm{H}$ and ${ }^{13} \mathrm{C}$ NMR spectra of 31
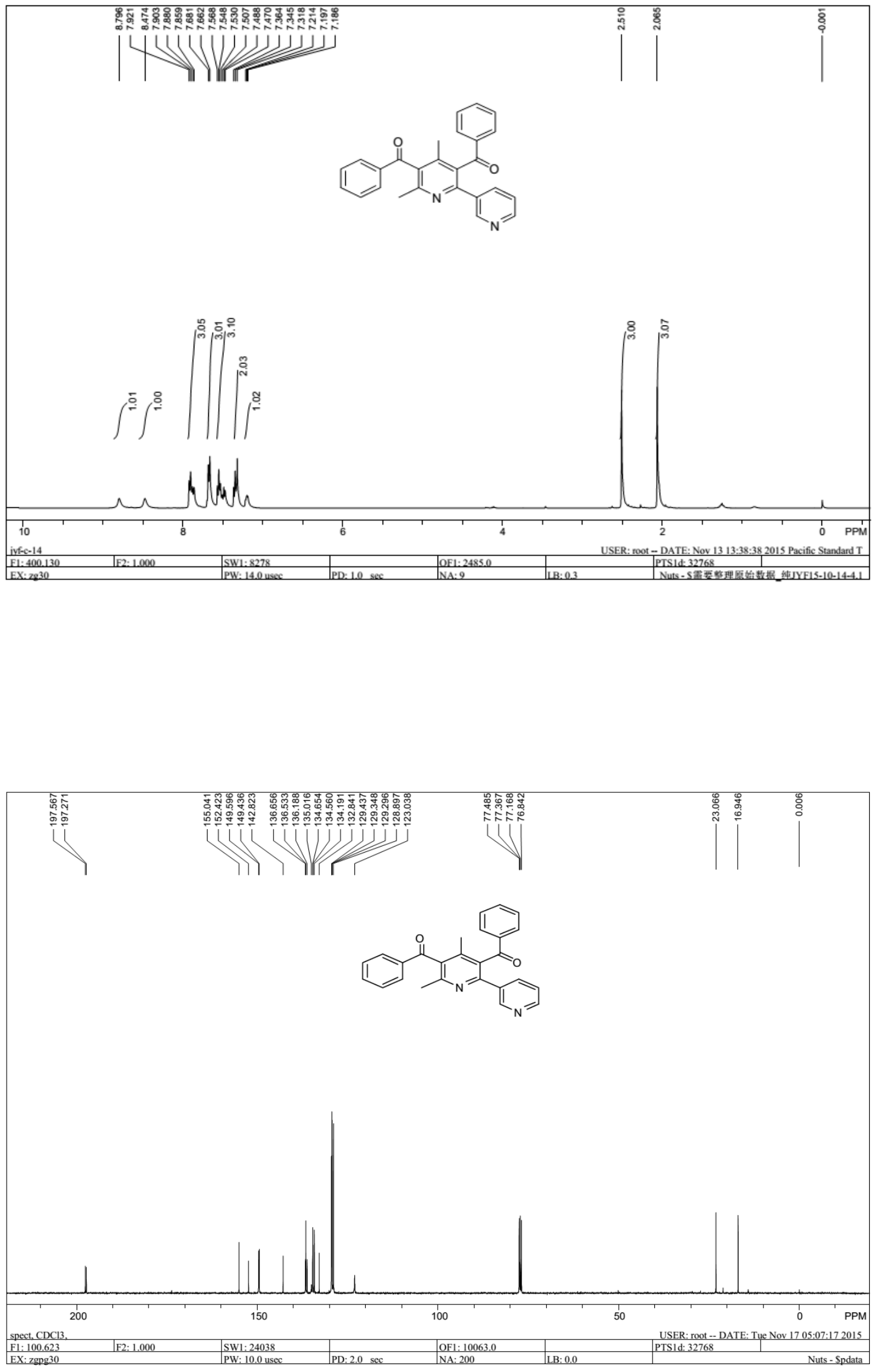
${ }^{1} \mathrm{H}$ and ${ }^{13} \mathrm{C}$ NMR spectra of $\mathbf{3 m}$
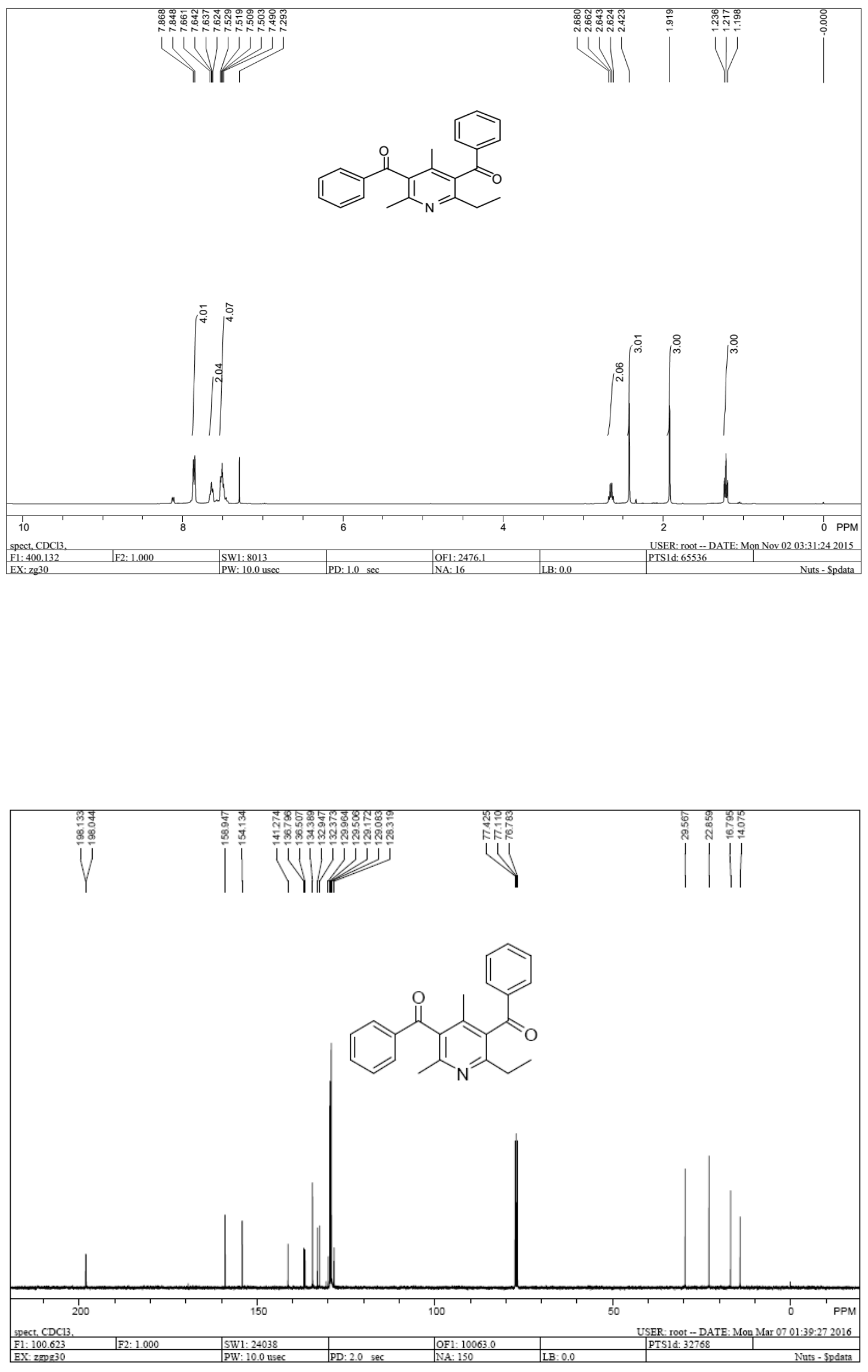
${ }^{1} \mathrm{H}$ and ${ }^{13} \mathrm{C}$ NMR spectra of $\mathbf{3 n}$
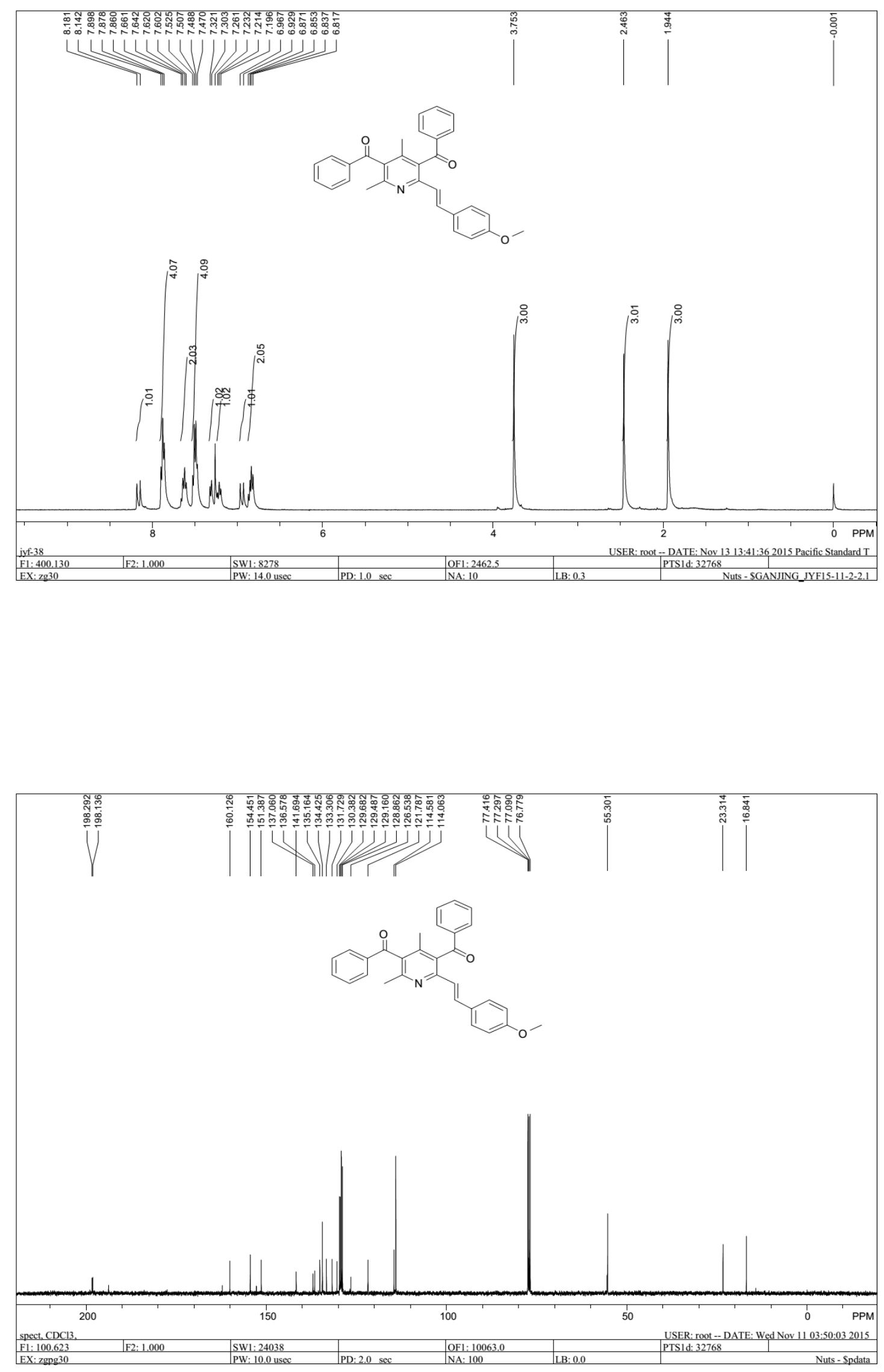
${ }^{1} \mathrm{H}$ and ${ }^{13} \mathrm{C}$ NMR spectra of $\mathbf{3 o}$
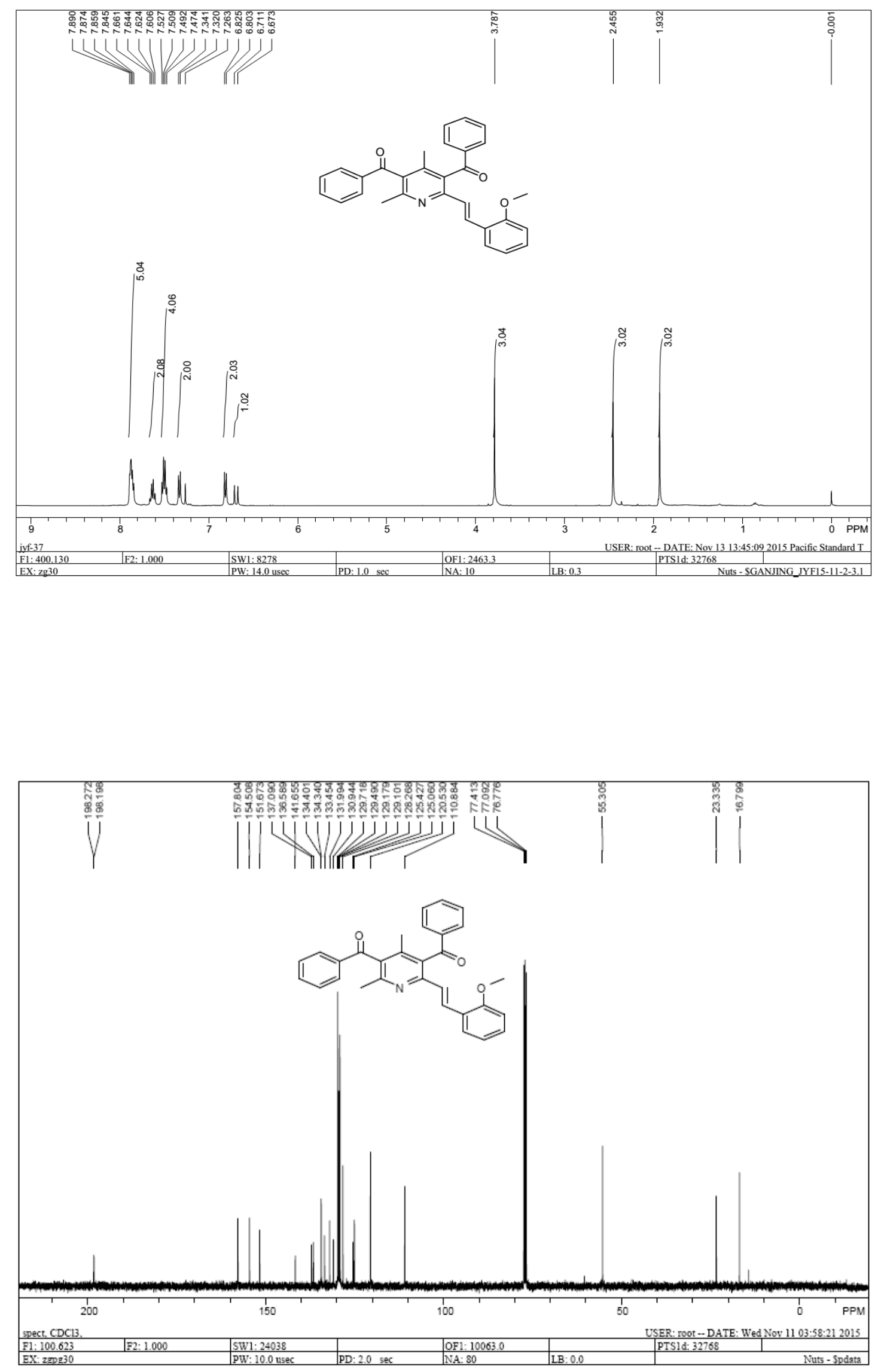
${ }^{1} \mathrm{H}$ and ${ }^{13} \mathrm{C}$ NMR spectra of $\mathbf{3 p}$
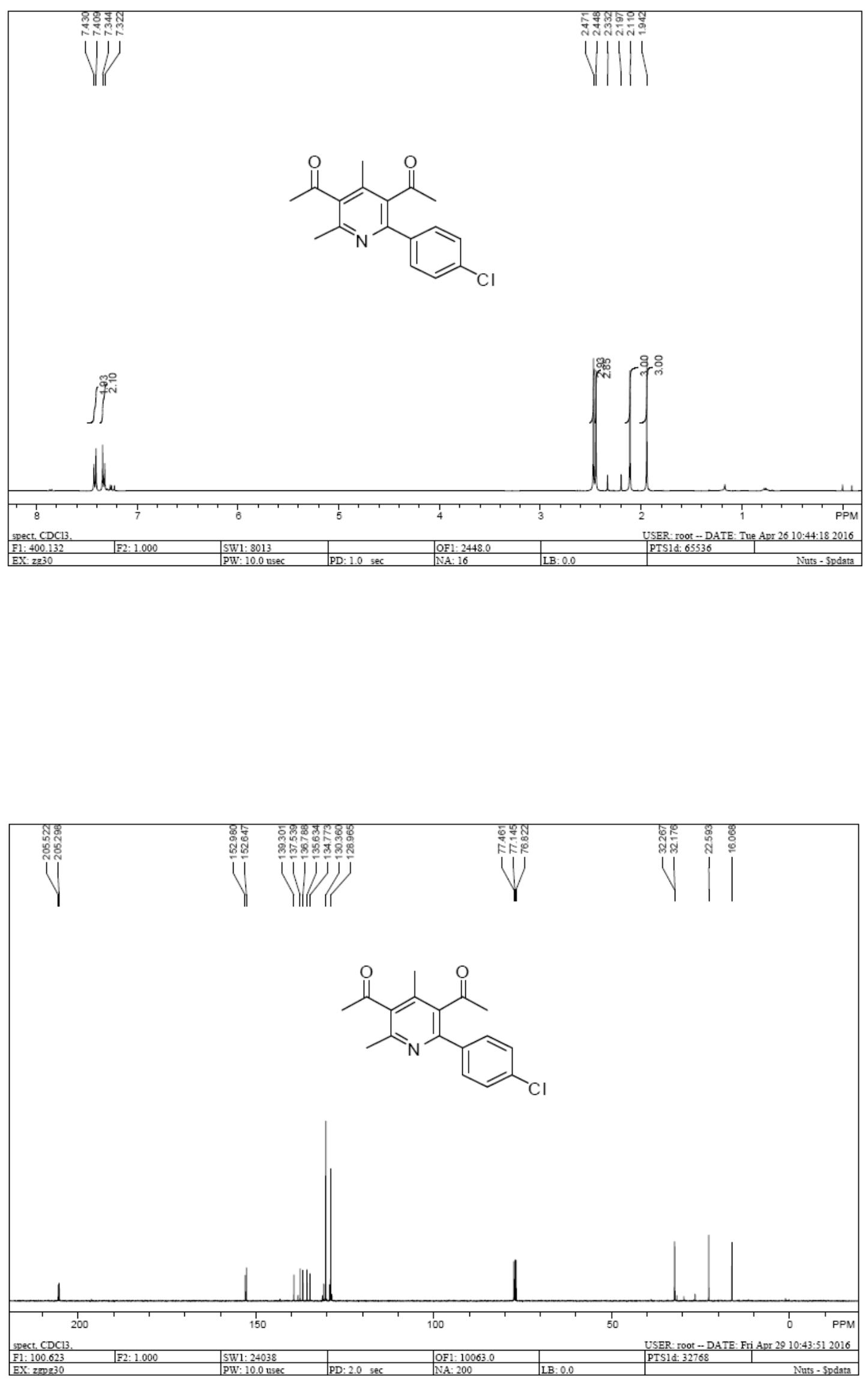
${ }^{1} \mathrm{H}$ and ${ }^{13} \mathrm{C}$ NMR spectra of $\mathbf{5 a}$
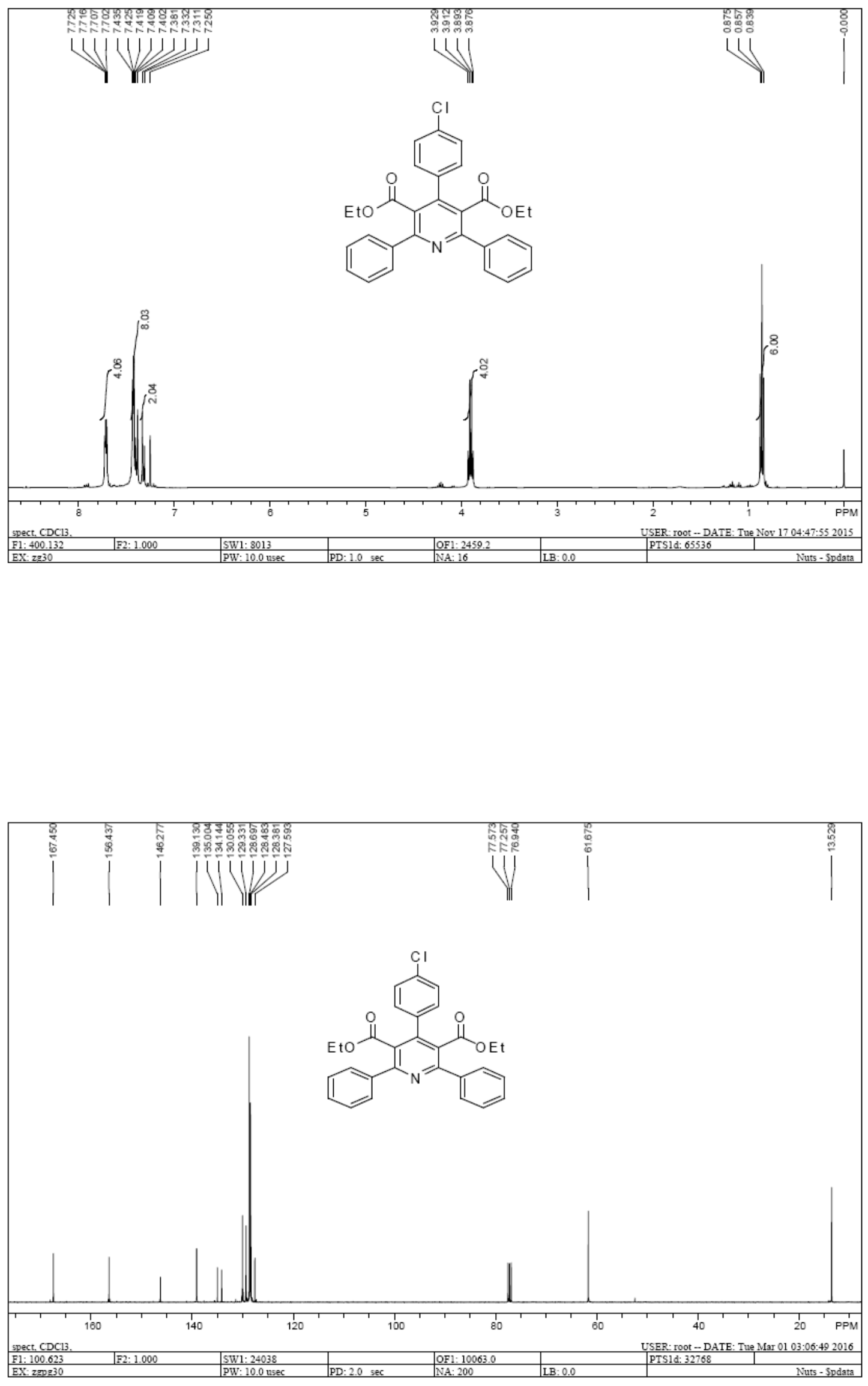
${ }^{1} \mathrm{H}$ and ${ }^{13} \mathrm{C}$ NMR spectra of $\mathbf{5 b}$
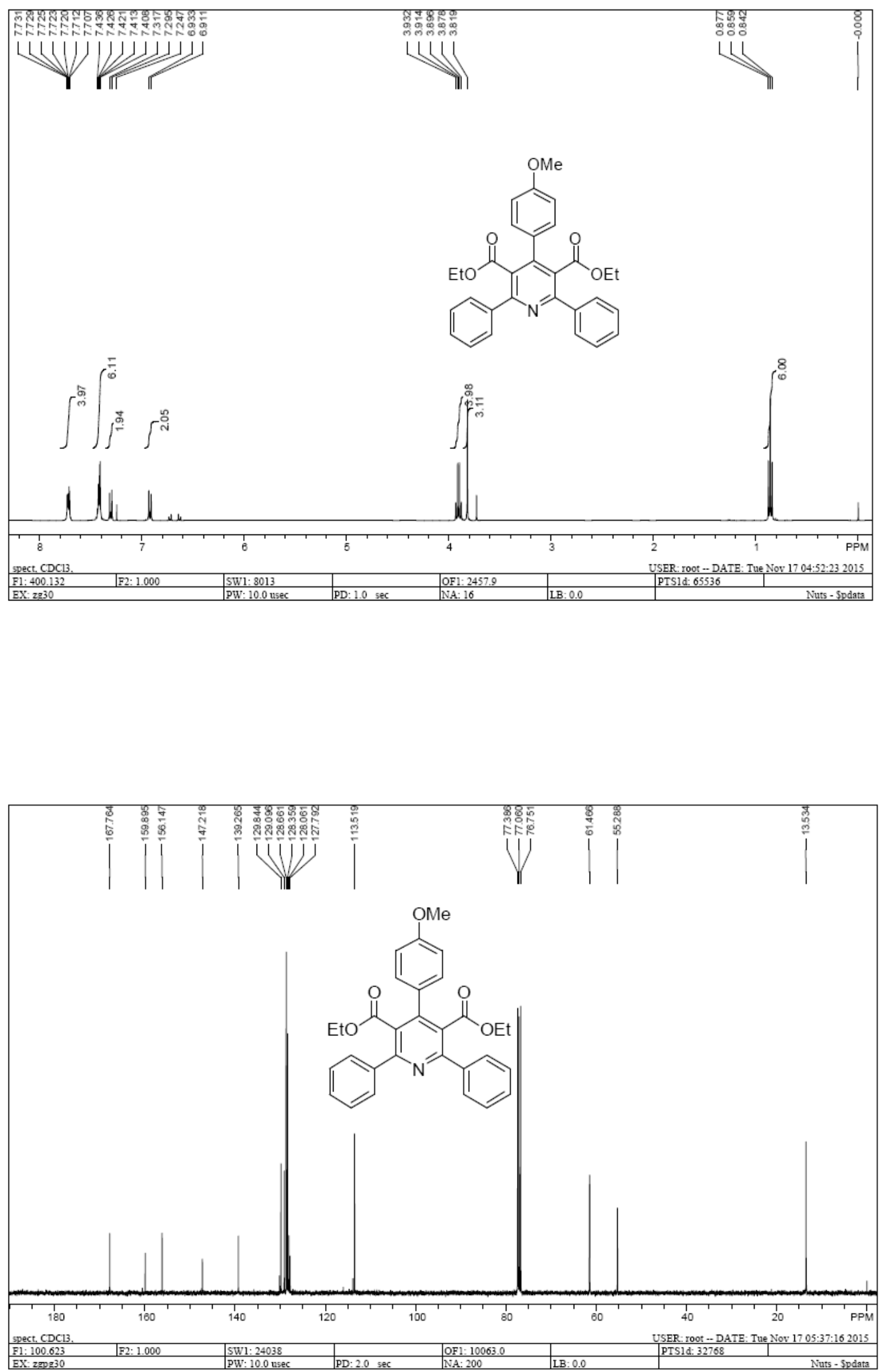
ORTEP view of the molecule structure of 3i (Displacement ellipsoids are drawn at the $45 \%$ probability level)

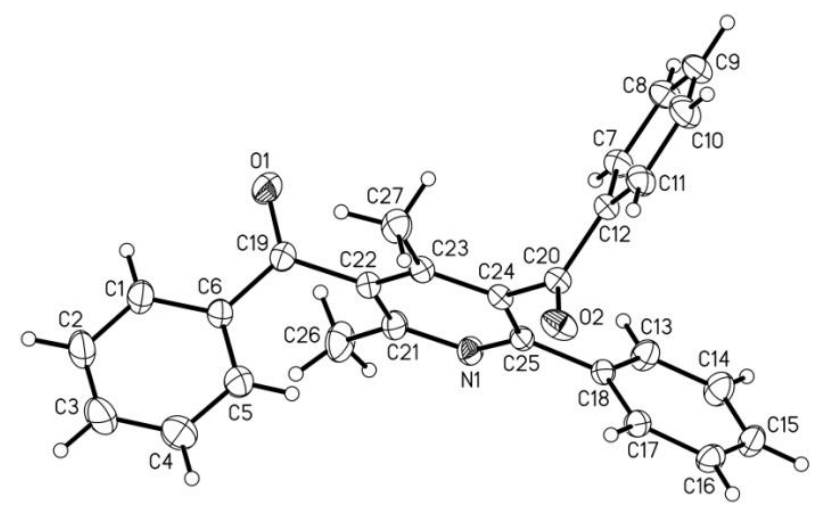

Suitable single crystal was selected under a stereomicroscope and fixed with epoxy cement on respective fine glass fiber, which is then mounted on a Rigaku R-Axis Rapid IP X-ray diffractometer with graphite-monochromated $\operatorname{Mo} K \alpha$ radiation $(\lambda=$ $0.71073 \AA$ ) for cell determination and subsequent data collection. The data are corrected for $L p$ and absorption effects. The SHELXS-97 and SHELXL-97 programs are used for structure solution and refinement [1]. The structure is solved by using direct methods, and all non-hydrogen atoms to be located in the subsequent difference Fourier syntheses. After several cycles of refinement, all hydrogen atoms associated with carbon atoms are geometrically generated, and the rest of the hydrogen atoms are located from the successive difference Fourier syntheses. Finally, all non-hydrogen atoms are refined with anisotropic displacement parameters by the full-matrix least-squares technique and hydrogen atoms with isotropic displacement parameters set to 1.2 times of the values for the associated heavier atoms. Detailed information about the crystal data and structure determination is summarized in Table 1.

[1] G. M. Sheldrick, SHELXS-97, Program for Crystal Stucture Refinement, and SHELXL-97, Program for Crystal Stucture Solution, Göttingen University, Germany (1997). 
Tabel 1 Summary of Crystal Data, Data collection, Structure and Refinement Details for $3 \mathbf{i}(T=295(2) \mathrm{K})$

\begin{tabular}{|c|c|}
\hline Compounds & 1 \\
\hline Empirical formula & $\mathrm{C}_{27} \mathrm{H}_{21} \mathrm{NO}_{2}$ \\
\hline Formula mass & 391.45 \\
\hline Crystal system & triclinic \\
\hline Space group & $P-1$ (no. 2) \\
\hline Description & Colorless platelet \\
\hline Crystal size (mm) & $0.49 \times 0.46 \times 0.21$ \\
\hline$a(\AA)$ & $8.366(2)$ \\
\hline$b(\AA)$ & $11.415(2)$ \\
\hline$c(\AA)$ & $12.415(2)$ \\
\hline$\square\left({ }^{\circ}\right)$ & $100.78(3)$ \\
\hline$\beta\left(^{\circ}\right)$ & $90.62(3)$ \\
\hline$\square\left({ }^{\circ}\right)$ & $106.74(3)$ \\
\hline Volume $\left(\AA^{3}\right)$ & $1052.9(4)$ \\
\hline$Z$ & 2 \\
\hline$D_{\text {calc }}\left(\mathrm{g} \cdot \mathrm{cm}^{-3}\right)$ & 1.235 \\
\hline$F(000)$ & 412 \\
\hline$\mu\left(\mathrm{mm}^{-1}\right)$ & 0.078 \\
\hline Refinement method & Full-matrix least-squares on $F^{2}$ \\
\hline$\theta$ Range $\left(^{\circ}\right)$ & $3.00-25.35$ \\
\hline Reflections collected & 8656 \\
\hline Unique reflections $\left(R_{\text {int }}\right)$ & $3837(0.0354)$ \\
\hline Data, restraints, parameters & $2588,0,271$ \\
\hline Goodness of fit on $F^{2}$ & 1.140 \\
\hline$R_{1}, w R_{2}[I \geq 2 \sigma(I)]^{a)}$ & $0.0466,0.1205$ \\
\hline$R_{1}, w R_{2}(\text { all data })^{a)}$ & $0.0795,0.1667$ \\
\hline$A, B$ values in weighting scheme $\left.{ }^{b}\right)$ & $0.0600,0.3858$ \\
\hline$\delta \rho_{\max }, \delta \rho_{\min }\left(\mathrm{e} \cdot \AA^{-3}\right)$ & $0.222,-0.207$ \\
\hline
\end{tabular}

${ }^{a)} R_{1}=\Sigma\left(\left|F_{\mathrm{o}}\right|-\left|F_{\mathrm{c}}\right|\right) / \sum\left|F_{\mathrm{o}}\right|, w R_{2}=\left[\sum w\left(F_{\mathrm{o}}^{2}-F_{\mathrm{c}}^{2}\right)^{2} / \Sigma w\left(F_{\mathrm{o}}^{2}\right)^{2}\right]^{1 / 2}$

${ }^{b)} w=\left[^{2}\left(F_{\mathrm{o}}^{2}\right)+(\mathrm{A} P)^{2}+B P\right]^{-1}$ with $P=\left(F_{\mathrm{o}}{ }^{2}+2 F_{\mathrm{c}}{ }^{2}\right) / 3$. 